\title{
Volume changes of concrete in interaction with sliding joint
}

\author{
Michal Kropacek ${ }^{1}$, Radim Cajka ${ }^{2}$, Petr Mynarcik ${ }^{3}$ \\ Department of Structures, Faculty of Civil Engineering, \\ VSB - Technical University of Ostrava, Ostrava, Czech Republic
}

E-mail: ${ }^{1}$ michal.kropacek@vsb.cz (corresponding author)

\begin{abstract}
The paper describes volume changes of cement plain concrete and steel fiber reinforced concrete with strength class C 30/37 in interaction with sliding joints. In the research experiment was performed large-dimensional specimens, on which volume changes were measured using string strain gauges. Below the large-dimensional specimens were designed sliding joints. The specimens were placed in a controlled laboratory environment and in an outdoor environment to simulate real conditions during construction and the measurements were carried out for several months. Volume changes of the concrete were compared to each other and significant influence of the sliding joints was observed. Significant influence on the development of volume changes also has dispersed reinforcement. Another part of the article is a comparison of experimental results with calculation models that allow to calculate the final shrinkage of concrete. Comparison results of volume changes with calculation models is important for demonstrating the effect of sliding joint, as currently valid calculation models do not consider the influence of subsoil and sliding joints, and the results are different as expected. For comparison model B4 (Bazant, 2015), model from technical standard EN 1992-1-1 (CSN EN 1992-1-1, 2006), model from fib model code 2010 (FIB, 2010) and model ACI (ACI, 2008) are used. The paper describes a unique experiment dealing with the influence of sliding joint on the development of volume changes of concrete from beginning of setting and hardening of concrete under precisely defined conditions, that allow comparison with calculation models and thus points to the shortcomings of the building practice.
\end{abstract}

Keywords: concrete technologies, volume changes, shrinkage, sliding joint, calculation models.

\section{Introduction}

Regarding the development of concrete technology, it is necessary to accurately describe all the processes that take place in cement concrete in the long run in terms of volume changes. The volume changes of the concrete, the binder of which is cement, are theoretically very well described and from the point of view of chemical processes, the whole process can be well described. In real conditions, it is possible to effectively minimize the negative impact of concrete shrinkage (especially possible formation of cracks). Shrinkage, as part of volume changes, takes place differently depending on the composition of the concrete and the surrounding conditions. Typical shrinkage types include plastic shrinkage, drying shrinkage and autogenous shrinkage. For completeness, it should also be noted carbonation shrinkage, but has negligible effect. Part of the volume changes is also swelling. From the point of hydration of cement swelling occurs at an early stage of setting and hardening and is due to the formation of hydration products. An integral part of volume changes is also the effect of temperature. The temperature has a significant effect on the course and intensity of hydration, more precisely on shrinkage, but also on hardened concrete it also has a significant influence on the mass expansion. (Aïtcin, 1998, 2008; Aïtcin \& Mindess, 2011; Collepardi, 2010; Tazawa, 1999; Vinkler \& Vitek, 2017).

As mentioned in the above paragraph, volume changes of cement concrete are theoretically well described, and calculation models are based on these findings. Calculation models allow to determine continuous shrinkage values and determine the final shrinkage, which is important for the design of concrete structures. Already when designing concrete constructions, it is necessary to assume that the concrete structure shrinks, and cracks can occur. In order to avoid the creation of untolerable cracks, it is necessary to use calculation models that allow to analyse the behaviour of the structure with different approaches. The article deals only with volume changes (simplified by shrinking), but shrinkage is only part of the phenomena (with creep etc.) through which the hardened concrete structure passes over time. The basic calculation model is the model of technical standard Eurocode 2 (CSN EN 1992-1-1, 2006), which is the most commonly used. The model from Eurocode 2 (CSN EN 1992-1-1, 2006) is followed by an improved model from the Model Code 2010 (FIB, 2010), which has different coefficients. In addition, the US model ACI

(C) 2019 Authors. Published by VGTU Press. This is an open-access article distributed under the terms of the Creative Commons Attribution (http://creativecommons.org/licenses/by/4.0/) License, which permits unrestricted use, distribution, and reproduction in any medium, provided the original author and source are credited. 
209R-92 (ACI, 2008) was used, which uses a different approach to calculation. Currently the most advanced model is model B4 (Bazant, 2015), which allows the calculation to include the most parameters and boundary conditions. The calculation models mentioned above were used by the authors in the experiment, but there are many other models, that do not differ significantly from selected representatives. Current models allow to work with a wide range of specimen sizes, boundary conditions and types of concrete, but for example do not allow dispersed reinforcement to be considered in the calculation (Bazant, 2015; Navratil, 2004; Navratil \& Cajka, 2017).

An important element that enters the development and course of volume changes is the subsoil and the sliding joint. The friction level at the base-subsoil interface has a fundamental influence on the course of volume changes in selected structures and the use of sliding joint allow this friction to be effectively reduced. In terms of volume changes more precisely shrinkage, this shrinkage can be further divided into free or restrained. This is an important division as friction in the base-subsoil interaction ensures that free shrinkage cannot occur in real conditions. The sliding joint may be understood as a simple subsoil treatment but may also be an intermediate layer which may be of different materials and different number of layers. There are basically two possible variants when using a sliding joint. The first is the use of several layers of different materials (e.g. PE foils with an interlayer of sand), where the resulting coefficient of friction enters the calculation. The second variant is to use asphalt-based materials (typically asphalt membranes) that have viscoelastic properties to reduce horizontal forces from shrinkage and creep. When using sliding joints with viscoelastic properties, temperature has a significant role in efficiency. A separate area in the use of sliding joints is prestressing of structures. Sliding joint allows free deformation during prestressing, which allows to introduce more prestressing into the structure (Bazant, Kristek, \& Vitek, 1992; Bilcik \& Sonnenschein, 2018; Bradac, 1991, 1996; Cajka, 2005; Cajka \& Manasek, 2005; Hornikova, Foglar, Kolisko, \& Kolar, 2016; Janulikova, Cajka, Mateckova, \& Stara, 2012; Sekanina \& Cajka, 2009; Schweighofer \& Kollegger, 2013; Smirakova, 2014).

In previous author's experiments, it was found that even the PE foil layer acts as an effective sliding joint and thus were significantly different measured volume change results in the laboratory and in outdoor environments simulating real casting conditions. This article builds on these findings and further develops the influence of sliding joints on volume changes of conrete. The results of the experimental part are further compared with the calculation models. Regarding the use of steel fibre reinforced concrete, it is necessary to add that the current calculation models do not allow the impact of dispersed reinforcement of concrete to be considered. A similar problem arises in the case of a sliding joint, because calculation models do not allow for the influence of subsoil and sliding joints to be included in the calculation (Kropacek, 2018; Kropacek \& Cajka 2018a, 2018b).

\section{Experimental part}

In the experimental part, six large-dimensional specimens were produced, which were made of two types of concrete. The first was steel fiber reinforced concrete C 30/37-X0 and the second was plain concrete C 30/37-XC4. The composition of the concretes is shown in Table 1. Concretes were designed in accordance with technical standard CSN EN 206 (CSN EN 206, 2014). The composition of the concretes correlates with each other (minor deviations of the individual components are caused using steel fibres), which was important for comparing and determining the effect of the dispersed reinforcement.

Table 1. Composition of concrete

\begin{tabular}{|l|c|l|c|}
\hline \multicolumn{2}{|c|}{ Steel fiber reinforced concrete C 30/37-X0 } & \multicolumn{1}{c|}{ Plain concrete C 30/37-XC4 } \\
\hline Component & $\begin{array}{c}\text { Amount } \\
\left(\mathrm{kg} / \mathrm{m}^{3}\right)\end{array}$ & \multicolumn{1}{c|}{ Component } & $\begin{array}{c}\text { Amount } \\
\left(\mathrm{kg} / \mathrm{m}^{3}\right)\end{array}$ \\
\hline Cement CEM I 42.5 R & 340 & Cement CEM I 42.5 R & 345 \\
\hline Fine aggregate 0/2 & 595 & Fine aggregate 0/2 & 570 \\
\hline Fine aggregate 0/4 & 255 & Fine aggregate 0/4 & 250 \\
\hline Coarse aggregate 4/8 & 110 & Coarse aggregate 4/8 & 130 \\
\hline Crushed coarse aggregate 8/16 & 495 & Crushed coarse aggregate 8/16 & 510 \\
\hline Crushed coarse aggregate 11/22 & 370 & Crushed coarse aggregate 11/22 & 335 \\
\hline Super plasticizing admixture & 3.3 & Super plasticizing admixture & 2.3 \\
\hline Water & 182 & Water & 189 \\
\hline w/c & 0.52 & w/c & 0.52 \\
\hline Steel fibres $-55 \mathrm{~mm}$ lenght & 25 & Steel fibres -55 mm lenght & - \\
\hline
\end{tabular}


The significance of the dispersed reinforcement is positive in terms of volume changes, since the reinforcement allows to retain tensile forces and thereby effectively reduce shrinkage. The composition of both concretes shows that they have the same water to cement coefficient, which is advantageous for comparison in terms of shrinkage (especially drying shrinkage) and using of dispersed reinforcement. The necessary basis for calculation models is also the determination of compressive strength and modulus of elasticity. For this purpose, test specimens were produced in the same time as concrete for large-dimensional specimens and the required parameters were set in the age of 7 and 28 days.

For the experimental part were produced large-dimensional specimens of dimensions $150 \times 500 \times 6000 \mathrm{~mm}$. Of the total of six specimens, three specimens were placed in the laboratory and three specimens were placed in outdoor environment. Concrete were cast into wooden formwork directly from the truck mixer using a through and compacted by a submersible vibrator. Two types of sliding joints were used on the bottom of the formwork in the following combination. The first combination of concrete and sliding joint was fibreconcrete and asphalt membrane. Second combination was fibreconcrete and two layers of polyethylene foil with geotextile interlayer. Third combination was plain concrete and asphalt membrane. In view of the viscoelastic behaviour of the asphalt, a $4 \mathrm{~mm}$ thick membrane of modified bitumen (SBS) was selected with sand on the surface and PE foil on the bottom. After the concrete was cast and the surface was aligned, the curing was started immediately. Specimens were covered with geotextile at the beginning of the setting and cured with water for 5 days. After this time geotextiles were removed, and lateral stripping was performed. The specimens in the laboratory were then kept under constant conditions with a temperature of $20 \pm 2{ }^{\circ} \mathrm{C}$ and relative humidity of air $55 \pm 5 \%$.

Volume changes including temperature sensing were measured using string strain gauged EDS-20-E. Three string strain gauges were placed in each specimen at a distance of $1.5 \mathrm{~m}$, measured from the edge of the specimen to the length. String strain gauges were at a height of $50 \pm 10 \mathrm{~mm}$ from the bottom of the specimen.

\section{Evaluation of results}

For the purpose of the article, the results of the experimental part were evaluated after 3 months (exactly 100 days), which is a sufficiently long time, but the measurement continues. In Figure 1 and Figure 2, the graph shows the measured volume changes of individual specimens using string strain gauges depending on the environment. Regarding the use of string strain gauges, it is necessary to emphazise that the measured values have been recalculated to the temperature correction. Consider the temperature correction is necessary due to the formation of hydration heat at the beginning of the hydration and extensibility of the concrete and in outdoor conditions due to the temperature changes due to climatic conditions. In view of the constant conditions in the laboratory, it is preferable to first describe the results in Figure 1. It can be seen from the graph that all three specimens in the laboratory started to swell at the beginning of hydration (setting) due to the increase in hydration heat and continuous water supply during water curing.

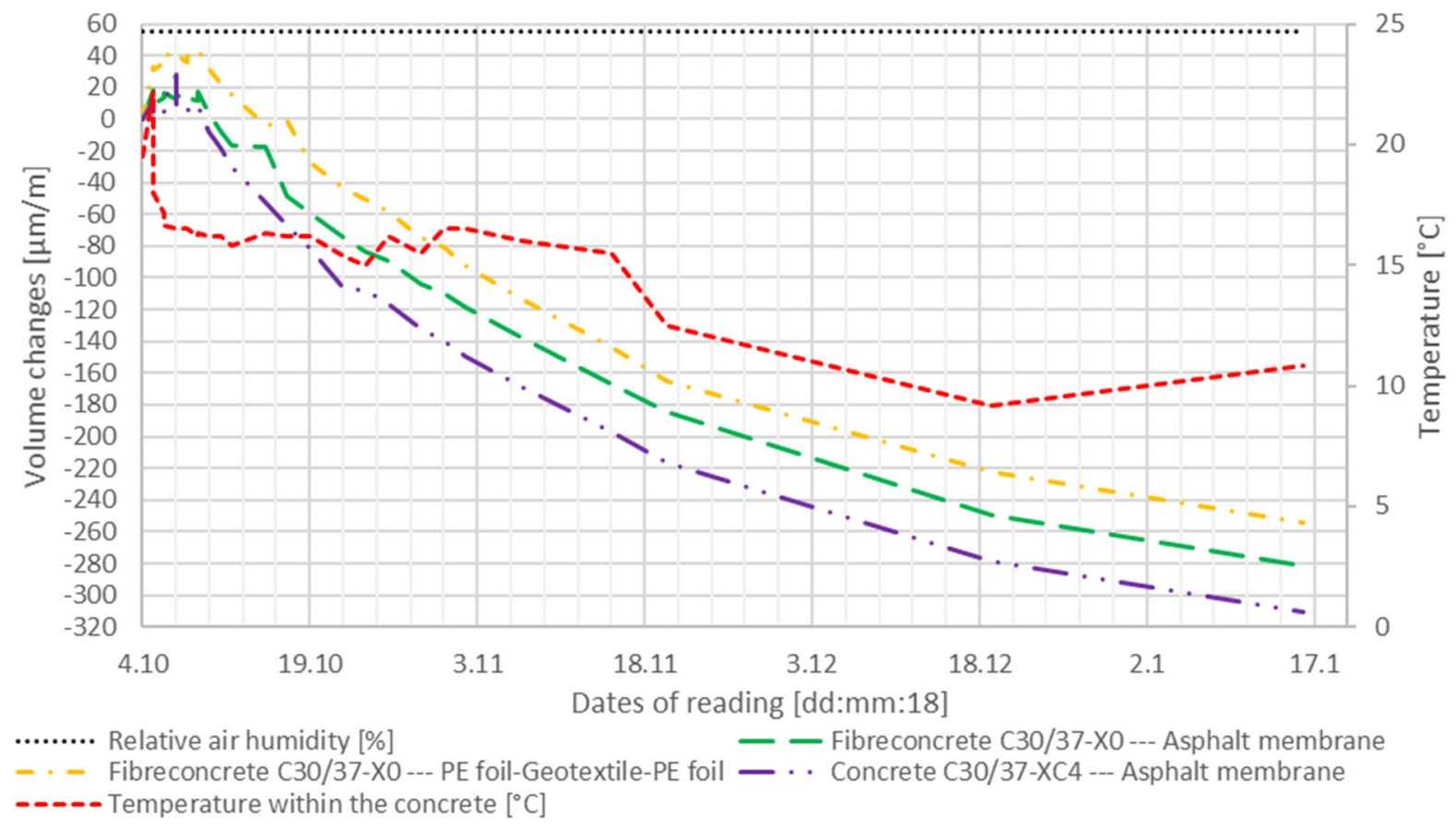

Figure 1. Volume changes of specimens in laboratory 
Swelling is also associated with the formation of new hydrating minerals such as etringite $\left(\mathrm{C}_{3} \mathrm{~A}\right)$ and dicalcium silicate $\left(\mathrm{C}_{2} \mathrm{~S}\right)$, but this phenomenon is more important in cement mortars (Kropacek, 2018). When water curing was finished ( 5 days), the specimens immediately began to shrink by drying. In accordance with the assumption of the behaviour of selected concrete, the largest shrinkage had plain concrete and asphalt membrane. The lowest shrinkage occurred in fibreconcrete and PE foil-Geotextile-PE foil, which can be explained by higher friction than in sliding joint from asphalt membrane in combination with the same fibreconcrete. The graph in Figure 1 clearly shows that drying shrinkage was regular and gradual. Other types of shrinkage (plastic, autogenous) can be neglected regarding composition of concrete and technological processes, which is fully consistent with theoretical knowledge.

Figure 2 shows a graph with volume changes of specimens exposed to outdoor climatic conditions. In general, the same explanations apply to the results as in the specimens in the laboratory, but other important factors are involved in the course of volume changes, and these are temperature and relative humidity of air. The graph shows that all specimens swell and shrink over time. Specimens are undoubtedly shrinking by drying, but the effect of extensibility due to changing temperature and water absorption due to precipitation is added to this phenomenon. The actual relative humidity of air that is higher, slows the progression of drying shrinkage. An important role has also the use of sliding joints that reduces friction. The graph of volume changes in the outdoor environment also shows the climatic conditions at the time of measurement. These climatic conditions are very variable and therefore it is also difficult to evaluate the behaviour of the specimens or any trend. The evaluation shows that the lowest volume change was the specimen of fibreconcrete with sliding joint PE foil-Geotextile-PE foil. This is an important result, as the same specimen in the laboratory also had the lowest volume changes. Since the steel fiber reinforced concrete effectively reduces volume changes, it is to some extent an expected behavior. The largest volume change had a specimen of plain concrete with sliding joint from an asphalt membrane. Again, the measured result corresponds to the results of the laboratory specimens. The results demonstrate the importance and functioning of the sliding joints and low friction provided by asphalt membrane.

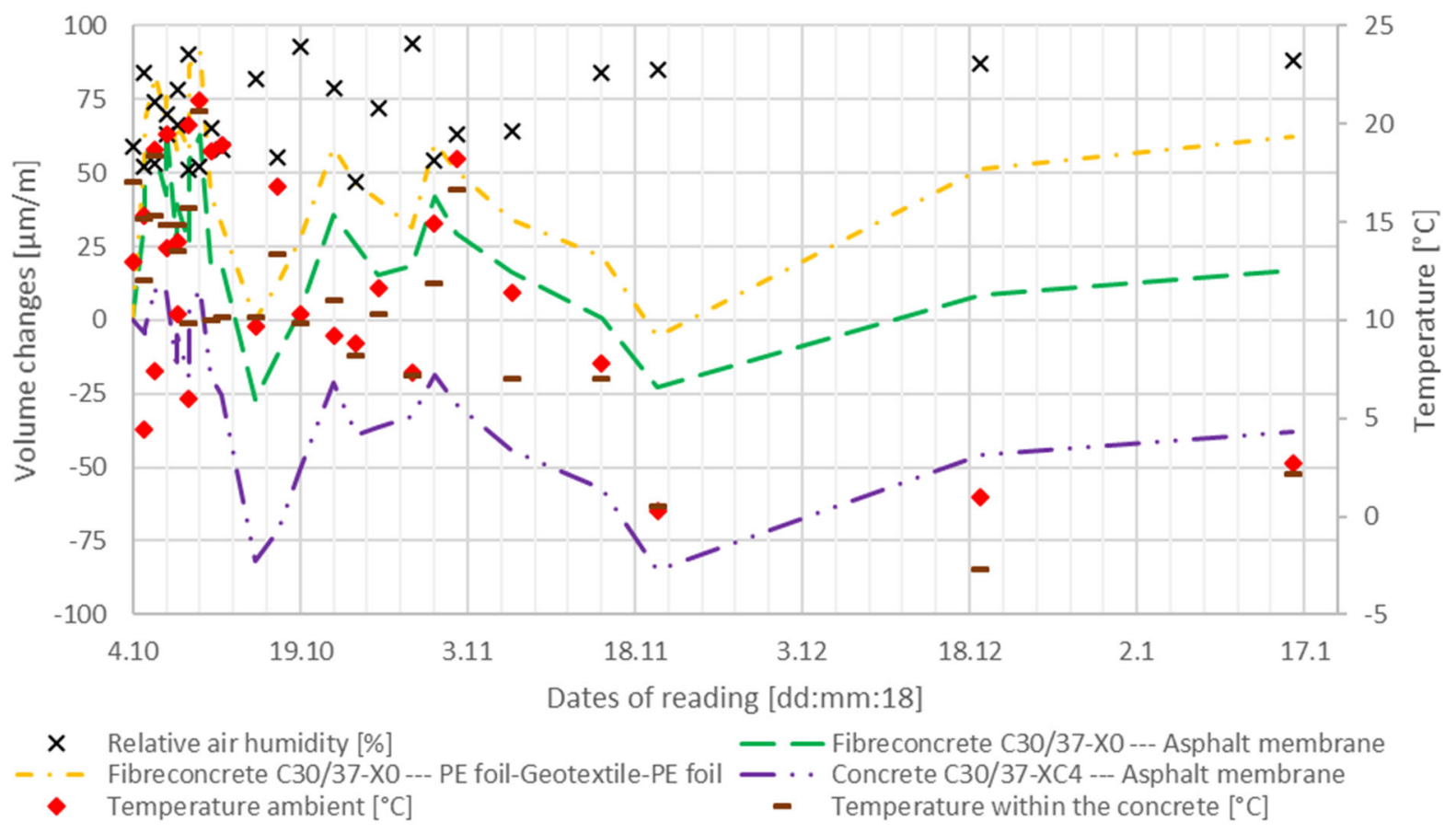

Figure 2. Volume changes of specimens in outdoor environment

\section{Comparison of results with calculation models}

The measured values of volume changes were further compared with the calculation models contained in the technical regulations for the design of concrete structures. Considering the large number of calculation models, the following models have been selected as representative: EC2 (CSN EN 1992-1-1, 2006), MC2010 (FIB, 2010), ACI 209R-92 (ACI, 2008) and B4 (Bazant, 2015). An important condition for comparison of results and subsequent evaluation is that the calculation models do not consider swelling within volume changes. Calculation models only consider shrinkage that beging at the end of curing. For this reason, it was necessary to recalculate the volume change results only to shrinkage. Specimens began to shrink after the end of curing, which was after five days. At this time, the highest swelling value was defined as "zero" and shrinkage began to count from then on. Therefore, the shrinkage values in Figure 3 and Figure 4 are greater than in Figure 1 and Figure 2. For calculation models were used input data resulting from the size of the specimens and the concrete composition (Table 1). Other important 
input values are: Time of curing - 5 days; Relative air humidity $(\mathrm{RH})$ in laboratory $-55 \%$; $\mathrm{RH}$ in outdor environment $-70 \%$ (long-term average RH in Czech Republic); Mean cylinder compressive strength after 28 days $27.9 \mathrm{MPa}$.

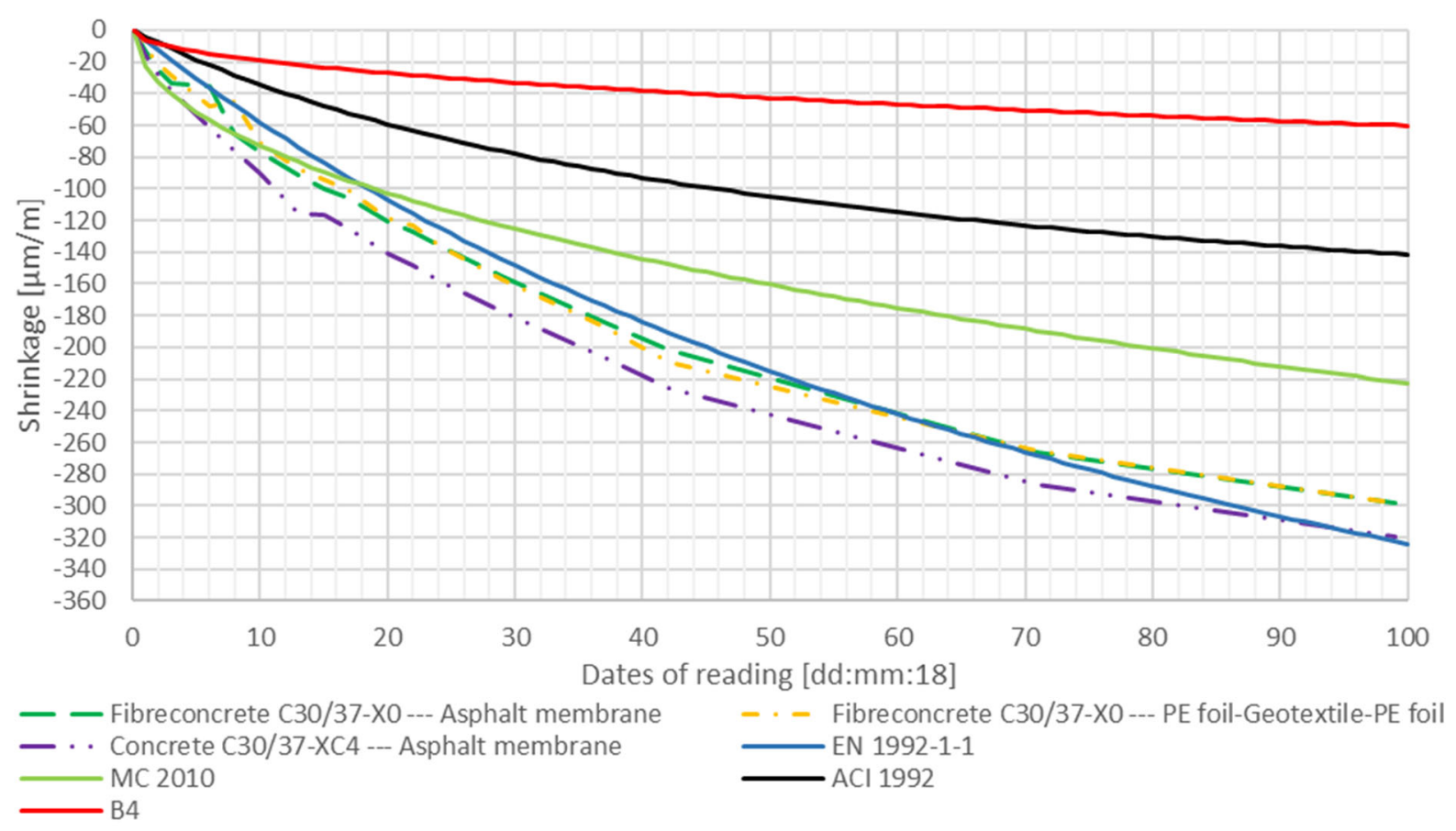

Figure 3. Comparison of shrinkage of specimens from the laboratory with calculation models

The graph in Figure 3 shows the comparison of the measured shrinkage values with calculation models. Bellow the picture is a description of the curves that are clearly marked in color and linetype. The measured results in the laboratory are significantly higher than assumed by the model B4 (Bazant, 2015). Conversely, the best results provide technical standard model EC2 (CSN EN 1992-1-1, 2006), which are closest to reality and meets the requirements of safe design and shrinkage modelling.

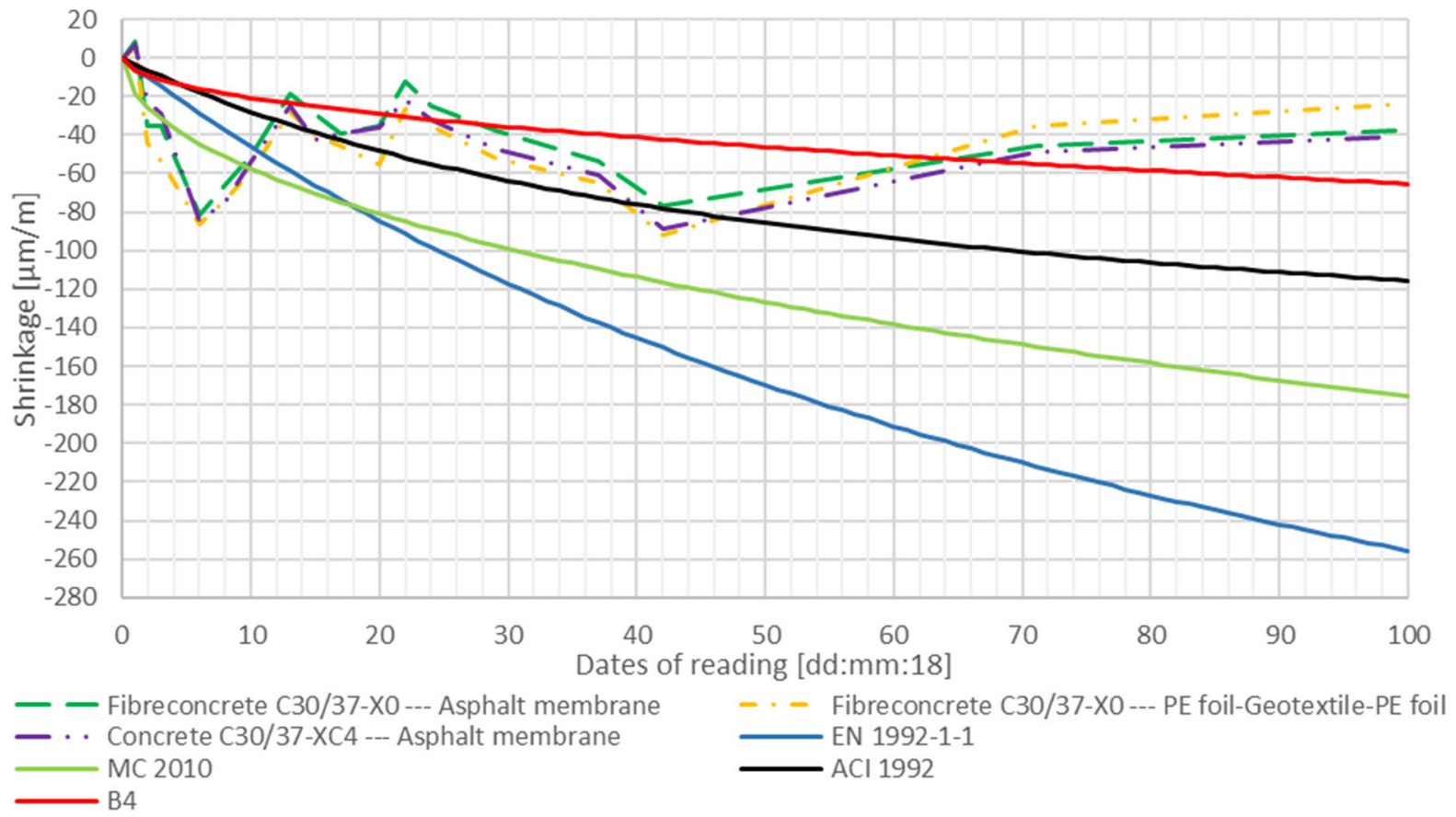

Figure 4. Comparison of shrinakge of specimens from the outdoor environment with calculation models 
In the graph of Figure 4, several other phenomena, such as relative air humidity, precipitation, temperature, enter the results. The sliding joint is gaining in importance due to alternating volume changes of specimens. Unlike specimens in the laboratory, model B4 (Bazant, 2015) is the closest to reality. The model from EC2 (CSN EN 1992-1-1, 2006) is very strict in this case. These results offer a very important finding. Since the trend and the course of curves from calculation models do not differ greatly between laboratory and outdoor conditions, the different behavior of the specimens can be attributed to the use of a sliding joint. As mentioned at the beginning of the article, calculation models do not consider the effects of subsoil and sliding joints.

\section{Conclusions}

The article describes the objectives of the experiment, which included the comparison of volume changes of different concrete depending on the subsoil and the use of sliding joint. The measurement of the specimens continues, but this partial evaluation makes it possible to provide comprehensive conclusions after sufficient time. The conclusion of the experiment can be divived into three parts. In the first part it is possible to evaluate the volume changes of concrete, when it can be stated the the steel fibre reinforced concrete has generally lower volume changes than plain concrete. The use of steel fibres makes it possible to effectively reduce volume changes in the early stages of setting and hardening of concrete even over a longer period (mainly due to shrinkage by drying). From the point of view of the sliding joint, which is the second important area of the experiment, it can be stated that the sliding joint has a significant impact on the development and course of volume changes. It is evident from the measured results that on the same concrete, the higher friction has a sliding joint in the compositon PE foil-Geotextile-PE foil than the asphalt membrane. This is particulartly evident in the laboratory environment where other influences could be reduced and only drying shrinkage occurred on the specimens.

The measured results were then compared with the calculation models, which is the author's long-term focus. Calculation models generally do not take into account the influence of subsoil and sliding joint, which confirmed the results of the experiment. The resuls are considerably contradictory, due to the use of sliding join that allows concrete specimens to have unbound (free) volume changes. Consequently, the volume changes of the real constructions may differ significantly from the calculations. The research will continue to evaluate other types of sliding joints in interaction with different concretes that reflect the needs of modern construction. The results will be further compared with the currently applicable calculation models.

\section{Acknowledgements}

This outcome has been achieved with the financial support of Ministry of Education, Youth and Sports by the project of "The conceptual research and development 2019 in the Faculty of Civil Engineering, VSB TU - Ostrava".

\section{References}

Aïtcin, P. C., \& Mindess, S. (2011). Sustainability of concrete. New York: Spon Press.

Aïtcin, P. C. (1998). High-performance concrete. London: E \& FN Spon. https://doi.org/10.4324/9780203475034

Aïtcin, P. C. (2008). Binders for durable and sustainable concrete. New York: Taylor \& Francis.

American Concrete Institute (ACI). (2008). Guide for modeling and calculating shrinkage and creep in hardened concrete. American Concrete Institute, Farmington Hills, MI.

Bazant, Z. (2015). RILEM draft recommendation: TC-242-MDC multi-decade creep and shrinkage of concrete. Model B4 for creep, drying shrinkage and autogenous shrinkage of normal and high strength concretes with multi-decade applicability. Materials and Structures, 48(4), 753-770. https://doi.org/10.1617/s11527-014-0485-2

Bazant, Z., Kristek, V., \& Vitek, J. (1992). Drying and cracking effects in box - girder bridge segment. Journal of Structural Engineering, 118(1), 305-321. https://doi.org/10.1061/(ASCE)0733-9445(1992)118:1(305)

Bilcik, J., \& Sonnenschein, R. (2018). Measures to reduce the formation of early-age through cracks in foundations slabs. Beton TKS, 18, 46-50.

Bradac, J. (1991). Designing of objects in the undermined area (Comment on CSN 73 0039). Prague: Publishing standards.

Bradac, J. (1996). Effects of undermining and protecting buildings. Part One. Ostrava: Technical publishing.

Cajka, R. (2005). Rheological properties of bituminous materials for slide joints, construction materials. Vancouver, Canada: ConMat' 05 and mindessb symposium.

Cajka, R., \& Manasek, P. (2005). Effect of friction in the subsoil on the tension of fiber concrete floors. In Conference Proceedings of the Conference with International Participation FC 2005 - Fiber concretes (vol. 3, pp. 237-242).

Collepardi, M. (2010). The new concrete. Italy: Grafiche Tinto-retto.

Czech Office for Standards, Metrology and Testing. (2014). Concrete - Specification, performance, production and conformity (CSN EN 206). Prague.

Czech Standards Institute. (2006). Eurocode 2: Design of concrete structures - Part 1-1: General rules and rules for building (CSN EN 1992-1-1). Prague. 
Hornikova, K., Foglar, M., Kolisko, J., \& Kolar, J. (2016). Experimental and numerical assessment of slab-on-grade friction coefficient. Beton TKS, 16, 42-49.

International Federation for Structural Concrete FIB. (2010). Model code 2010: first complete draft. Lausanne, Switzerland: Fédération internationale du béton.

Janulikova, M., Cajka, R., Mateckova, P., \& Stara, M. (2012). Modelling of foundation structures with sliding joint using results of laboratory tests of asphalt belts. Transactions of the V $\breve{S} B$ - Technical University of Ostrava, Civil Engineering Series, 12, 510. https://doi.org/10.2478/v10160-012-0002-x

Kropacek, M., \& Cajka, R. (2018a). Experimental measurement and calculation of volume changes of concrete specimens. WSEAS Transactions on Applied and Theoretical Mechanics, 13, 29-36.

Kropacek, M., \& Cajka, R. (2018b). Measurement of volume changes of cement concrete in large-dimensional samples. Solid State Phenomena, 272, 102-106. https://doi.org/10.4028/www.scientific.net/SSP.272.102

Kropacek, M. (2018). Experimental measurement of volume changes of cement composites using portland cements from different locations. WSEAS Transactions on Applied and Theoretical Mechanics, 13, 193-198.

Navratil, J., \& Cajka, R. (2017). Crack control in reinforced concrete liquid retaining structures. Materials Science Forum, 893, 410-415. https://doi.org/10.4028/www.scientific.net/MSF.893.410

Navratil, J. (2004). Structural analysis of bridges, legitimate conservatism and obsolete theories. Concrete Engineering International, 8(1), 17-19.

Schweighofer, A., \& Kollegger, J. (2013). Reibungsfreie Gleitlagerung für vorgespannte Bodenplatten. Beton und Stahlbetonbau, 108(5), 335-345. https://doi.org/10.1002/best.201200070

Sekanina, D., \& Cajka, R. (2009). Interaction between prestressed floor and subsoil. Transactions of the V̌̌B - Technical University of Ostrava. Civil Engineering Series, 9, 17-24.

Smirakova, M. (2014). Comparison of the shear resistance in the sliding joint between asphalt belts and modern PVC foils. Applied Mechanics and Materials, 501-504, 945-948. https://doi.org/10.4028/www.scientific.net/AMM.501-504.945

Tazawa, E. (1999). Autogenous shrinkage of concrete. New York: E \& FN Spon.

Vinkler, M., \& Vitek, J. L. (2017). Drying shrinkage of concrete elements. Structural Concrete, 18(1), 92-103. https://doi.org/10.1002/suco.201500208 